\title{
Mapping the Visual World of Fishes
}

\author{
John D. Pettigrew ${ }^{a}$ Shaun P. Collin ${ }^{a, b}$

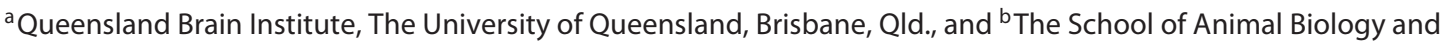 \\ the Oceans Institute, The University of Western Australia, Crawley, W.A., Australia
}

\footnotetext{
The two classic papers discussed in this essay:

Collin SP, Pettigrew JD (1988): Retinal topography in reef teleosts. I. Some species with well-developed areae but poorly developed streaks. Brain Behav Evol 31:269-282.

Collin SP, Pettigrew JD (1988): Retinal topography in reef teleosts. II. Some species with prominent

Horace Barlow has a dictum that one should deal separately with the figures and text when preparing a paper, in order to accommodate readers with different preferences for the written word over the graphics, and vice versa. Our two Brain, Behavior and Evolution Citation Classics papers (cited over 240 times) lie toward the end of the spectrum that emphasizes graphics. Shaun Collin's aesthetic and information-packed artwork means that visits to the accompanying text are all but redundant, as comparisons between the visual systems of the different fish species are all made against the same graphical backdrop showing the diversity of visual habitats on a typical coral reef, within which one can locate the species in question.

The work was carried out at the University of Queensland's Research Station on Heron Island, a coral cay on the southern Capricornia section of the Great Barrier Reef. The laboratory is only a hundred meters from the reef itself and was beautifully equipped (and became even more so after it was rebuilt after a fire). The proximity of the reef enabled us to observe (on snorkel and scuba) a myriad of reef teleosts in their natural habitat and pose questions about how each species viewed its visual world. We adapted the retinal wholemount technique of Stone [1981], which had been used to assess the density of ganglion cells across the whole retina, for fishes and then compared the acute zones of teleosts from a range of habitats. We defined an acute zone as a localized region of high retinal ganglion cell density, which provides high spatial resolving power within a specific part of a species' visual field.

One of the clear conclusions of our study (split over two papers) was a verification of Abbie Hughes' [1977] 'terrain theory', extended to an aquatic environment. We found that fish species with elongated, horizontal streaks of increased retinal ganglion cell density all lived in a habitat where there was a clear view of the ocean bottom, just like their terrestrial equivalents who live in open environments with a clear, uninterrupted view of the ground or horizon. In contrast, fish from enclosed or more three-dimensional environments or habitats, such as predators 'pouncing' from concealment in rocky holes, lacked a horizontal streak and had concentrically organized isodensity contours of ganglion cell density. These results showed a surprisingly close match between the topographic arrangement of retinal ganglion cells and the symmetry of each species' perceived aquatic environment.

We decided to provide a graphical template of the coral reef environment and presented the outline (silhouette) of each species we examined superimposed on the template to convey their visual environment. Common control features in the repeated habitat diagrams (compare parts I and II) allow the reader to quickly peruse the retinal data from many different species of fishes against the standardized graphical data on its habitat, and so arrive at one's own conclusions about the generality of the results. The accompanying figure 1 illustrates a reef species which possesses a well-developed horizontal streak across the retinal meridian (in addition to a specialized retinal zone for acute vision in the upper temporal retina). This species frequently ventures outside the protection of the reef, indicated by its silhouette in the right-hand side of the template. We believe this study fits perfectly with the aims and scope of the journal, and we appreciated the opportunity to publish these papers at that time.

\section{References}

Hughes A (1977): The topography of vision in mammals of contrasting lifestyles: comparative optics and retinal organization; in Crescitelli F (ed): The Visual System in Vertebrates, Handbook of Sensory Physiology. New York, Springer, vol VII/5, pp 613-756.

Stone J (1981): The Wholemount Handbook, a Guide to the Preparation and Analysis of Retinal Whole Mounts. Sydney, Maitland.

\section{KARGER 125}

C 2015 S. Karger AG, Base

0006-8977/15/0854-0215\$39.50/0
Dr. John D. Pettigrew

Queensland Brain Institute University of Queensland Brisbane, QLD 4072 (Australia)

E-Mail j.pettigrew@uq.edu.au 


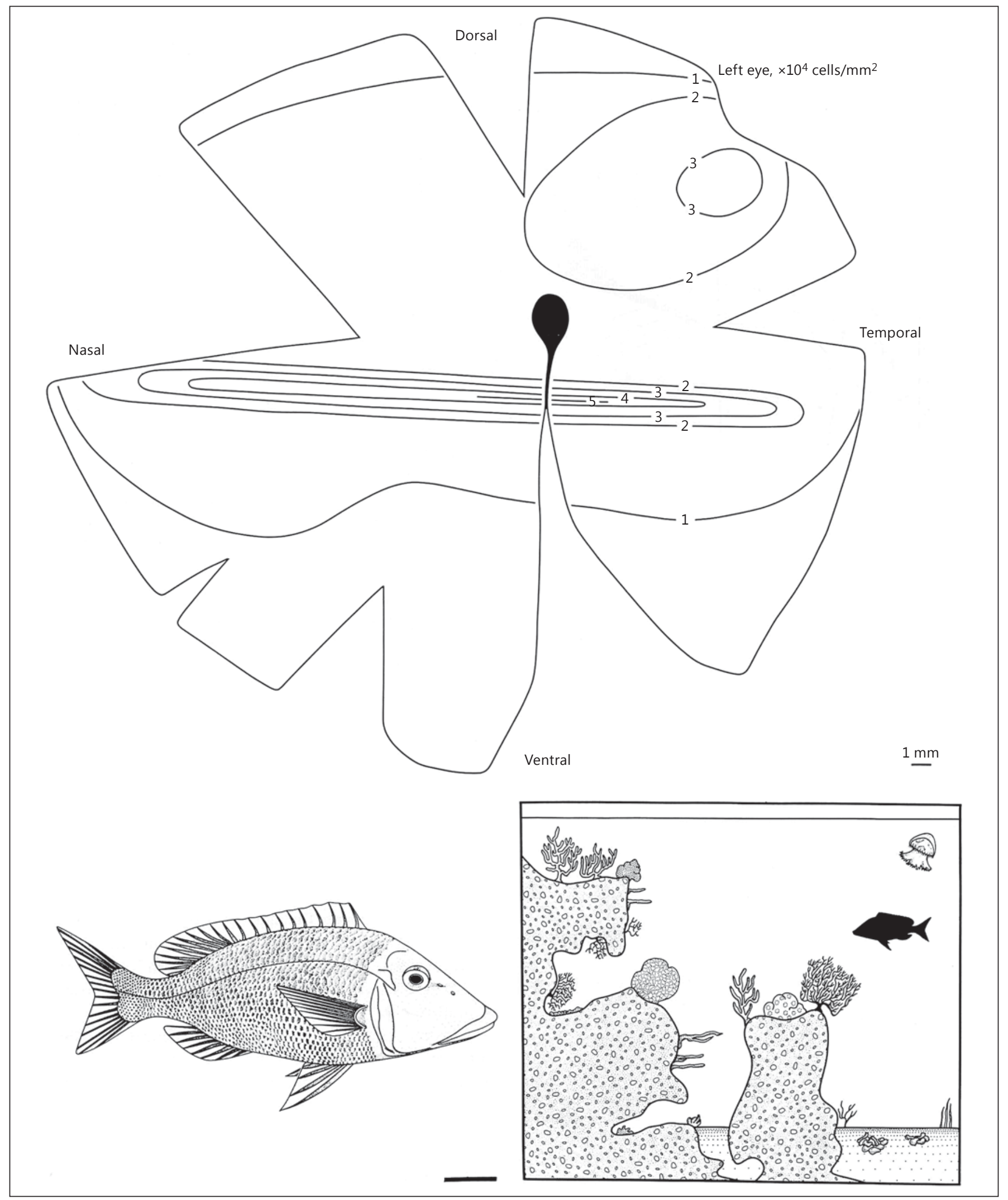

Fig. 1. Lethrinus chrysostomas. 